\title{
Age at menarche, age at menopause, reproductive years and risk of fatal stroke occurrence among Chinese women: the Guangzhou Biobank Cohort Study
}

Zhi-bing $\mathrm{Hu}^{1 \dagger}$, Ze-xiong $\mathrm{Lu}^{1,2+}$ and Feng Zhu ${ }^{1 *}$

\begin{abstract}
Background: The relationship between women's reproductive characteristics and stroke events is unclear. We aimed to investigate age at menarche, age at menopause and number of reproductive years in relation to fatal stroke occurrence in the Guangzhou Biobank Cohort Study.

Methods: In total, 16,504 postmenopausal women without stroke, heart disease or a cancer history at baseline were included and followed up for a median of 12.0 years. After review of available records, 222 stroke deaths were recorded. Cox proportional hazards regression was used to assess the associations between the risk of fatal stroke occurrence and age at menarche, age at menopause and number of reproductive years.

Results: In the whole cohort, compared with those aged 15 years at menarche, an increased risk of fatal stroke among women at menarche showed respectively in those aged 12 years (aHR (adjusted hazard ratio) $=1.86,95 \%$ confidence interval $(\mathrm{Cl}) 0.96-3.60$ ), aged 13 years ( $\mathrm{aHR}=1.69,95 \% \mathrm{Cl} 0.98-2.92)$, aged 17 years $(\mathrm{aHR}=1.83,95 \% \mathrm{Cl} 1.10-$ 3.05 ) and aged $\geq 18$ years ( $a \mathrm{HR}=1.66,95 \% \mathrm{Cl} 1.03-2.70)$, wherein the associations revealed an atypically U-shaped; similar U-shaped association to the cohort of postmenopausal women born before 1940 released a range of incremental risks of fatal stroke in women at menarche aged $\leq 12$ years ( $\mathrm{aHR}=3.68,95 \% \mathrm{Cl} 1.68-8.05)$, aged 13 years $(\mathrm{aHR}=2.11,95 \% \mathrm{Cl} 1.02-4.34)$, aged 14 years $(\mathrm{aHR}=2.07,95 \% \mathrm{Cl} 1.04)$, aged 17 years $(\mathrm{aHR}=2.30,95 \% \mathrm{Cl} 1.20-4.39)$ and aged 18 years ( $a \mathrm{HR}=2.50,95 \% \mathrm{Cl} 1.37-4.57$ ), respectively. Compared with menopausal women aged $51-52$ years, those aged $<43$ years at menopause had an increased risk for fatal stroke among postmenopausal women born in and after $1940(\mathrm{aHR}=1.64,95 \% \mathrm{Cl} 0.97-2.78)$ and postmenopausal women born before 1940 ( $\mathrm{aHR}=1.97,95 \% \mathrm{Cl}$ 1.05-3.69). Additionally, compared with those with 32-34 reproductive years, women with $\leq 28$ reproductive years had an increased risk for fatal stroke in the whole cohort ( $\mathrm{aHR}=1.91,95 \% \mathrm{Cl} 1.28-2.86)$ and the cohort of postmenopausal women born before 1940 ( $\mathrm{aHR}=1.79,95 \% \mathrm{Cl} 1.15-2.80)$.
\end{abstract}

Conclusions: Younger and older age at menarche, younger age at menopause and fewer reproductive ages were related to an increased risk of fatal stroke in postmenopausal women.

\footnotetext{
*Correspondence: chifengzhu@hotmail.com

${ }^{\dagger}$ Zhi-bing Hu and Ze-xiong Lu are joint first authors

1 Department of Internal Medicine and Central Laboratory, Guangzhou

Twelfth People's Hospital, No. 1 Tianqiang St., Huangpu Rd.,

Guangzhou 510620, China

Full list of author information is available at the end of the article
}

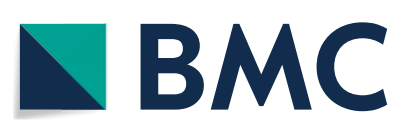

(c) The Author(s) 2021. Open Access This article is licensed under a Creative Commons Attribution 4.0 International License, which permits use, sharing, adaptation, distribution and reproduction in any medium or format, as long as you give appropriate credit to the original author(s) and the source, provide a link to the Creative Commons licence, and indicate if changes were made. The images or other third party material in this article are included in the article's Creative Commons licence, unless indicated otherwise in a credit line to the material. If material is not included in the article's Creative Commons licence and your intended use is not permitted by statutory regulation or exceeds the permitted use, you will need to obtain permission directly from the copyright holder. To view a copy of this licence, visit http://creativecommons.org/licenses/by/4.0/. The Creative Commons Public Domain Dedication waiver (http://creativeco $\mathrm{mmons}$.org/publicdomain/zero/1.0/) applies to the data made available in this article, unless otherwise stated in a credit line to the data. 
Keywords: Stroke, Ischaemic, Menarche, Menopause, Reproductive

\section{Background}

In China, the life expectancy of women is 79.9 years, which is approximately 6.5 years longer than that of men [1]. Stroke is a leading cause of death in China [2] and is considered to be a sexually dimorphic disease [3]. Compared with men, women more easily suffer from cerebrovascular disease [4], have a higher stroke incidence [5] and have poorer functional outcomes for intravenous thrombolysis (IVT)-treated ischaemic stroke [6]. One study revealed that sex had a modifying effect on mortality in diabetic patients with first-ever ischaemic stroke, showing an increased risk of long-term mortality among women [7].

Menarche is the beginning, and menopause is the end of a woman's reproductive timeline, and the reproductive years, which is the interval between menarche and menopause, is a woman's natural reproductive window. Recent studies have reported that early menarche is associated with an increased mortality or incidence risk of stroke [8-15], though there are conflicting reports [12, 16-23]. Additionally, a U-shaped association [24] and an increased risk of stroke incidence have been found in those with late menarche $[19,25]$. However, early menarche showed a $16 \%$ lower but an $18 \%$ higher risk of stroke among women born during the 1920s-1940s and women born in the 1950s, respectively, and a U-shaped association among women born in the 1960s-1970s [14]. Fewer reproductive years was also associated with stroke mortality or incidence [10,12, 25-27], though there were inconsistencies in results $[8,19]$. Thus, these previous studies on women showed a mixed relationship between reproductive characteristics and stroke events.

Besides an anomalous increase during the 1958-61 national famine, age at menarch droped but age at menopause increased with years among Chinese women [28]. Although one study in age at menarch was released [14], the relationship between Chinese women's reproductive characteristics and stroke events is not comprehensive. Here, we aimed to systematically assess the associations between age at menarche, age at menopause, and number of reproductive years and the risk of fatal stroke occurrence in healthy postmenopausal Chinese women.

\section{Methods}

\section{Data source and participants}

Details of the Guangzhou Biobank Cohort Study (GBCS) have been reported previously [29]. Briefly, this is an on-going prospective cohort study including permanent Guangzhou residents aged 50 years or older that aims to examine environmental and genetic determinants of chronic diseases. The GBCS is a collaborative project among the Guangzhou 12th Hospital and the Universities of Hong Kong and Birmingham. Those who were receiving treatment for life-threatening diseases, such as cancer, or did not provide informed consent, were excluded. A total of 30,518 older Chinese individuals including 22,067 women in Guangzhou were recruited at baseline. The baseline (from September 1st, 2003, to February 28th, 2008) included a face-to-face computerassisted interview by trained nurses on lifestyle, family and personal medical history; assessments of anthropometrics and blood pressure; and a series of laboratory tests, including fasting plasma glucose and lipids. Physical activity was assessed by means of the Chinese version of the International Physical Activity Questionnaire (IPAQ) and was classified into inactive, moderately active and physically active [30].

\section{Exposure indicators}

The ages at menarche and menopause, which is the end of a woman's menstrual cycle and fertility wherein both natural and induced menopause included by the removal of uterus and ovaries, were recorded in years (per the Gregorian calendar and related interpretation of age) and rounded during data collection to the nearest year (e.g., 13 years represents the onset of menarche from 12 years 6 months to 13 years 5 months) [31]. The number of reproductive years was generated by subtracting age at menarche from age at menopause. Data on each woman's history of oral contraceptive (OC) use (ever, never), hormone replacement therapy, hysterectomy and ovarian or breast surgery were also recorded.

\section{Outcome indicators}

Information on underlying causes of death up to December 31st, 2017, was obtained mostly via record linkage with the Guangzhou Centres for Disease Control and Prevention (GZCDC). Because there was no other information for stroke severity, infarct volume, lesion site or infectious complications, fatal stroke occurrence was chosen as the primary outcome of this study. Death causes were coded according to the 10th revision of the International Classification of Diseases (ICD) as follows: I60 I69 for stroke; I60.0 I62.9 and I69.0 I69.2 for haemorrhagic stroke; I63.0 I63.9 and I69.3 for ischaemic stroke; and the other codes for unclassified stroke. When the death certificates were not issued by medical institutions, the causes were verified by GZCDC as part 
of their quality assurance programmed by cross-checking past medical history and conducting verbal autopsy by 5 senior clinicians from Guangzhou Twelfth People's Hospital, the Universities of Hong Kong, China, and Birmingham, UK.

To examine the extent to which baseline factors explained the associations of stroke, ischaemic stroke and haemorrhagic stroke, we included the factors in different models. Model 1 was a crude hazard ratio model without adjustment for any confounders. Model 2 contained a multivariate adjustment for factors including age, diabetes, hypertension, dyslipidaemia, smoking, alcohol consumption, physical activity, body mass index, self-rated health, education, job, family income, number of children and oral contraceptive pill use.

\section{Statistical analysis}

Cox proportional hazards regression was used to analyse the association between age at menarche and age at menopause, reproductive years and the risk of fatal stroke. The age at menarche was categorized into 7 age groups: $\leq 12,13,14,15,16,17$, and $\geq 18$ years [14]. The age at menopause was categorized into 5 age groups: $<43$, $43-47,48-50,51-52$, and $\geq 53$ years [26]. The reproductive years were categorized into 5 age groups: $\leq 28$, $29-31,32-34,35-37$, and $\geq 38$ years. Fewer reproductive years was defined as the lowest deciles [19]. We chose 1940 as cut-point and added two birth cohorts(details on the two birth cohorts showed on Additional file 1: Table 4), because age at menarche among Chinese women droped with years, besides an anomalous increase during the 1958-61 national famine, and the menarche ended among most women born before 1940 [14]. Covariates included age, diabetes, hypertension, dyslipidaemia, smoking, alcohol consumption, physical activity, body mass index, self-rated health, education, job, family income, number of children and oral contraceptive pill use. Similar to a previous Chinese population study [28], our cohort showed that age at menarche decreased and that age at menopause increased in younger generations. Thus, further analysis was conducted by birth cohort; by smoking status (never smoker with additional adjustments for childhood passive smoking exposure, which is linked to an earlier age at both menarche [32] and menopause [33], and stroke mortality [34]). A sensitivity analysis was conducted after exclusion of those with removal of the uterus, ovaries, or breast masses (benign or malignant) or those who received hormone replacement therapy. All analyses were performed using STATA (version 14.0; StataCorp LP, College Station, TX, USA). All $\mathrm{p}$ values were 2 sides, and statistical significance was defined as $P<0.05$.

\section{Results}

\section{Baseline characteristics}

In total, 22,067 (72.5\% of whole participants, original sample size) female participants comprising 20,343 (sample size without other exclusion criteria) postmenopausal women were screened. Among 2419 patient exclusions, 244 were lost to follow-up and had an unknown vital status, 157 had a history of stroke, 1741 had heart disease or peripheral vascular disease, 363 had cancer, and 1334 had incomplete information on diabetes, hypertension, dyslipidaemia, smoking, alcohol consumption, physical activity, body mass index, self-rated health, education, job, family income, number of children and oral contraceptive pill use. A total of 16,504 participants who were free of stroke at baseline were included in this study, they had higher rates of $\leq$ primary education and manual jobs, lower rates of hypertension, and had a lower family income, compared with those exclusions (Additional file 1: Table 5). After a median follow-up of 12.0 (Q25 (the 25th quartile):10.7, Q75 (the 75th quartile):13.4) years, 222 stroke deaths (95 ischaemic, 82 haemorrhagic and 45 unclassified) were recorded (Fig. 1). Among the postmenopausal women, the mean age was 61.4 (6.8) years, and the age at menarche was 15.1 (2.1) years, with 15.7 (2.1) years among those born before 1940 and 14.9 (2.0) years among those born in 1940 or later); the age at menopause was 49.5 (3.8) years, with 48.9 (4.1) years among those born before 1940 and 49.7 (3.6) years among those born in 1940 or later); and the number of reproductive years was 34.3 (4.3) years, with 33.2 (4.6) years among those born before 1940 and 34.8 (4.0) years among those born in 1940 or later (Additional file 1: Tables 4-5).

The baseline characteristics of the participants according to age at menarche are presented in Table 1. Compared with those aged 15 years at menarche, those with early menarche $(\leq 12)$ were younger; had lower rates of $\leq$ primary education and manual jobs; had a higher family income, lower proportion of women with a number of children born $>3$, and a higher number of reproductive years; and had higher proportions of current smokers, alcohol consumers and women with physical activity. Compared with those aged 15 years at menarche, those with late menarche $(\geq 18)$ were older, comprised more current smokers, and were more likely to engage in physical activity; had higher rates of $\leq$ primary education and manual jobs; had a higher proportion of women with a number of children $>3$ and lower family income; had lower rates of hypertension, diabetes, current drinking, and oral contraceptive pill use; and had fewer reproductive years. 
20343 women participants at postmenopausal recruited for baseline of the Guangzhou Biobank Cohort Study

1334 participants with incomplete information on diabetes, hypertension, dyslipidemia, smoking, alcohol drinking, physical activity, body mass index, self-rated health, education, job, family income, number of children and oral contraceptive pill use

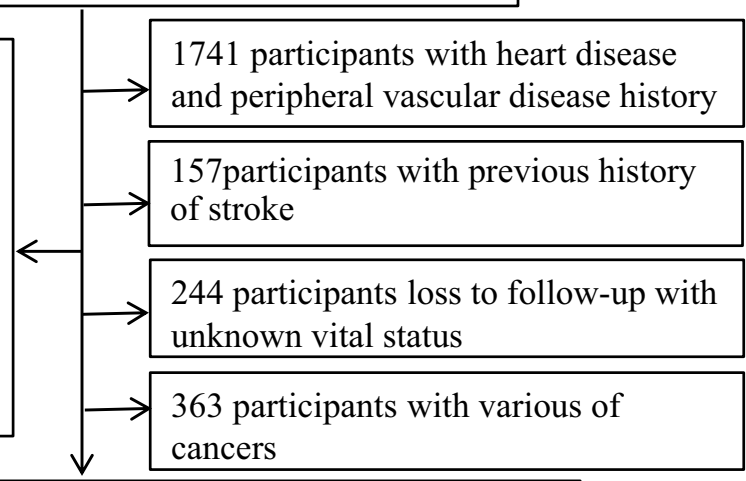

16504 participants at baseline were recorded in this study (from September 2003 to February 2008)

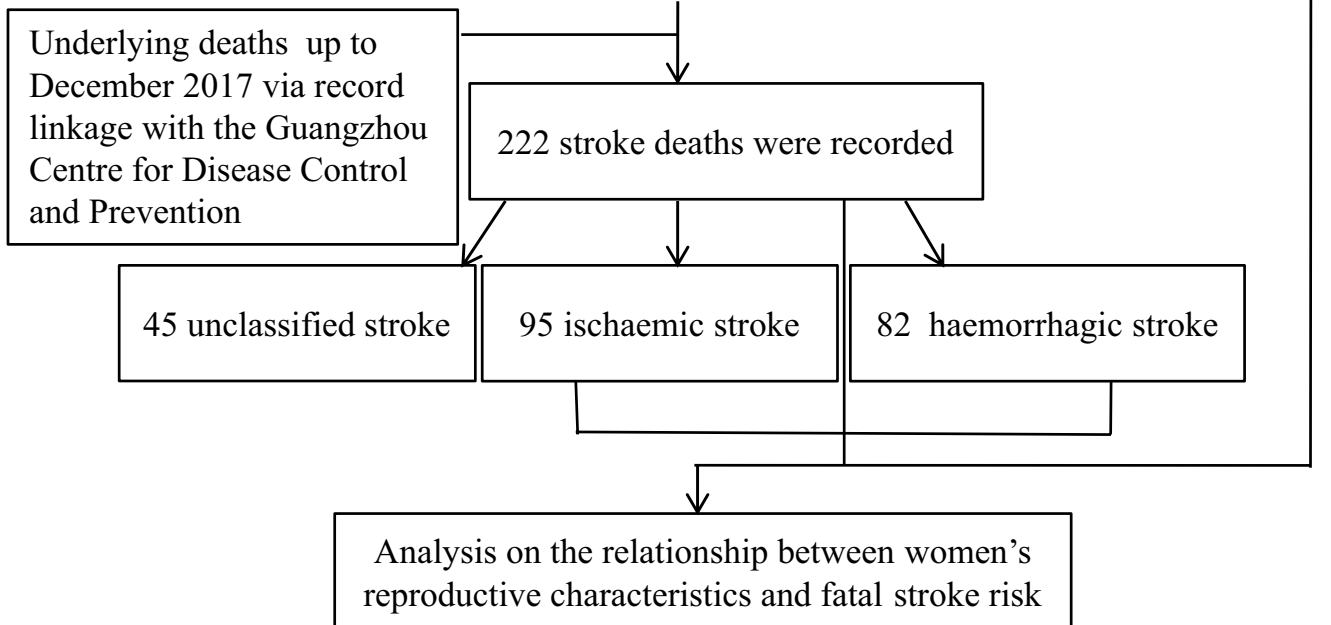

Fig. 1 Flow diagram of participants selected for the analysis of this study

\section{Menarche in relation to fatal stroke occurrence}

Menarche in relation to fatal stroke occurrence is presented in Table 2, which seemed to be U-shaped. In the whole cohort, compared with those aged 15 years at menarche, an increased risk of fatal stroke among women at menarche showed respectively in those aged 12 years $(\mathrm{aHR}=1.86,95 \%$ CI $0.96-3.60)$, aged 13 years $(\mathrm{aHR}=1.69,95 \mathrm{CI} \% 0.98-2.92)$, aged 17 years $(\mathrm{aHR}=1.83,95 \% \mathrm{CI} 1.10-3.05)$ and aged $\geq 18$ years ( $\mathrm{aHR}=1.66,95 \%$ CI 1.03-2.70); similar U-shaped association to postmenopausal women born before 1940 released a range of incremental risks of fatal stroke in those at menarche aged $\leq 12$ years $(\mathrm{aHR}=3.68,95 \% \mathrm{CI}$ $1.68-8.05)$, aged 13 years $(\mathrm{aHR}=2.11,95 \% \mathrm{CI} 1.02-4.34)$, aged 14 years $(\mathrm{aHR}=2.07,95 \% \mathrm{CI} 1.04)$, aged 17 years $(\mathrm{aHR}=2.30,95 \%$ CI 1.20-4.39) and aged 18 years $(\mathrm{aHR}=2.50,95 \%$ CI 1.37-4.57). However, there were no significant associations between fatal stroke and menarche in those born in 1940 or later. All these associations were still observed in a sensitivity analysis after exclusions of patients with removal of the uterus, ovaries, or breast masses (benign or malignant) or who received hormone replacement therapy (Additional file 1: Table 1).

\section{Menopause in relation to fatal stroke occurrence}

Table 3 shows menopause in relation to fatal stroke occurrence. Compared with menopausal women aged 51-52 years, those with earlier menopause at age $<43$ years had an increased risk of fatal stroke $(\mathrm{aHR}=1.64,95 \%$ CI 0.97-2.78). Compared with menopausal women aged 51-52 years, postmenopausal women born before 1940 showed a significant association with the risk of fatal stroke for those of age $<43$ 
Table 1 Baseline characteristics by age at menarche of participants in the GBCS

\begin{tabular}{|c|c|c|c|c|c|c|c|c|}
\hline \multirow[t]{2}{*}{ Characteristics } & \multirow[t]{2}{*}{ Overall } & \multicolumn{7}{|c|}{ Age at menarche (years) } \\
\hline & & $\leq 12$ & 13 & 14 & 15 & 16 & 17 & $\geq 18$ \\
\hline Number, $\mathrm{n}$ & 16,504 & 1368 & 2662 & 2849 & 2787 & 2667 & 1720 & 2451 \\
\hline Age (years) ${ }^{b}$ & 61.4 & 59.0 & 59.4 & 60.2 & 61.7 & 62.1 & 63.1 & 64.1 \\
\hline Hypertension, \% ${ }^{b}$ & 27.0 & 27.6 & 27.8 & 27.9 & 27.6 & 27.6 & 26.7 & 23.8 \\
\hline Diabetes, $\%^{\mathrm{a}}$ & 13.1 & 13.7 & 12.3 & 13.3 & 13.6 & 13.8 & 14.5 & 11.3 \\
\hline Dyslipidaemia, $\%{ }^{b}$ & 85.7 & 87.4 & 87.6 & 86.8 & 85.9 & 85.2 & 84.2 & 82.7 \\
\hline $\operatorname{BMI}\left(\mathrm{kg} / \mathrm{m}^{2}\right)^{\mathrm{b}}$ & 23.8 & 24.3 & 23.9 & 23.8 & 23.8 & 23.8 & 23.8 & 23.6 \\
\hline Good/very good self-rated health, $\%^{c}$ & 82.7 & 82.6 & 83.5 & 83.0 & 82.5 & 82.5 & 81.2 & 82.8 \\
\hline Oral contraceptive pill use (ever), \% ${ }^{\mathrm{b}}$ & 17.8 & 17.6 & 18.9 & 19.7 & 17.4 & 19.0 & 16.7 & 14.2 \\
\hline Current smoker, $\%^{\mathrm{b}}$ & 1.9 & 2.0 & 1.7 & 1.5 & 1.7 & 2.5 & 1.6 & 2.3 \\
\hline Current drinking, $\%^{\mathrm{b}}$ & 20.6 & 26.4 & 23.0 & 22.2 & 19.9 & 18.6 & 18.1 & 17.5 \\
\hline Active physical activity, $\%^{c}$ & 52.6 & 52.1 & 53.0 & 52.2 & 50.9 & 52.2 & 54.1 & 54.1 \\
\hline Education $\leq$ primary, $\%{ }^{\mathrm{b}}$ & 49.9 & 31.5 & 33.3 & 38.6 & 50.0 & 58.2 & 65.1 & 71.8 \\
\hline Manual job, \% ${ }^{b}$ & 54.5 & 43.3 & 47.1 & 47.7 & 54.8 & 58.3 & 62.2 & 66.6 \\
\hline Family income $<30,000 \mathrm{CNY} /$ year, $\%^{\mathrm{b}}$ & 38.3 & 33.5 & 34.9 & 35.0 & 38.0 & 41.6 & 43.7 & 41.3 \\
\hline Number of children born $>3, \%^{\mathrm{b}}$ & 21.4 & 8.6 & 10.9 & 13.2 & 21.2 & 26.5 & 31.8 & 36.7 \\
\hline Age at menopause (years) $)^{b}$ & 49.5 & 49.0 & 49.4 & 49.6 & 49.6 & 49.6 & 49.5 & 49.5 \\
\hline Reproductive years (years) ${ }^{\mathrm{b}}$ & 34.3 & 37.2 & 36.4 & 35.6 & 34.6 & 33.6 & 32.5 & 30.9 \\
\hline
\end{tabular}

${ }^{\mathrm{a}} P<0.05 ;{ }^{\mathrm{b}} P<0.01 ;{ }^{\mathrm{c}} P>0.05$; hypertension: systolic blood pressure, $\geq 140 \mathrm{mmHg}$, diastolic blood pressure, $\leq 90 \mathrm{mmHg}$, medication or diagnosed; diabetes: fasting blood glucose $\geq 7$ or medication or diagnosis; dyslipidaemia: total cholesterol $\geq 5.2 \mathrm{mmol} / \mathrm{L}$, triglyceride $\geq 1.7 \mathrm{mmol} / \mathrm{L}$, low density lipoprotein $\geq 3.4 \mathrm{mmol} / \mathrm{L}$, high density lipoprotein $<1.0 \mathrm{mmol} / \mathrm{L}$, medication or diagnosis; $B M /$ body mass index

Table 2 Association between fatal stroke occurrence and age at menarche in the GBCS

\begin{tabular}{|c|c|c|c|c|c|c|c|}
\hline & \multicolumn{7}{|c|}{ Age at menarche (years) } \\
\hline & $\leq 12$ & 13 & 14 & 15 & 16 & 17 & $\geq 18$ \\
\hline Total cohort & 1368 & 2662 & 2849 & 2787 & 2667 & 1720 & 2451 \\
\hline No. of deaths & $14(0.010)$ & $28(0.011)$ & $28(0.010)$ & $25(0.009)$ & $39(0.015)$ & $37(0.022)$ & $51(0.021)$ \\
\hline $\begin{array}{l}\text { Model } 1 \\
\text { (HR, 95\% Cl) }\end{array}$ & $\begin{array}{l}1.22(0.64-2.35) \\
P=0.55\end{array}$ & $\begin{array}{l}1.19(0.70-2.05) \\
P=0.52\end{array}$ & $\begin{array}{l}1.13(0.66-1.94) \\
P=0.66\end{array}$ & 1.00 & $\begin{array}{l}1.63(0.99-2.69) \\
P=0.06\end{array}$ & $\begin{array}{l}2.39(1.44-3.97) \\
P=0.001\end{array}$ & $\begin{array}{l}2.34(1.45-3.77) \\
P=0.001\end{array}$ \\
\hline $\begin{array}{l}\text { Model } 2 \\
(\mathrm{HR}, 95 \% \mathrm{Cl})\end{array}$ & $\begin{array}{l}1.86(0.96-3.60) \\
P=0.07\end{array}$ & $\begin{array}{l}1.69(0.98-2.92) \\
P=0.06\end{array}$ & $\begin{array}{l}1.41(0.82-2.42) \\
P=0.22\end{array}$ & 1.00 & $\begin{array}{l}1.41(0.85-2.34) \\
P=0.18\end{array}$ & $\begin{array}{l}1.83(1.10-3.05) \\
P=0.02\end{array}$ & $\begin{array}{l}1.66(1.03-2.70) \\
P=0.04\end{array}$ \\
\hline $\begin{array}{l}\text { Born }<1940^{\$} \\
\text { cohort }\end{array}$ & 261 & 511 & 669 & 898 & 887 & 677 & 1035 \\
\hline No. of deaths & $12(0.046)$ & $16(0.031)$ & $20(0.030)$ & $14(0.016)$ & $27(0.030)$ & $28(0.042)$ & $47(0.045)$ \\
\hline $\begin{array}{l}\text { Model } 1 \\
(\mathrm{HR}, 95 \% \mathrm{Cl})\end{array}$ & $\begin{array}{l}3.01(1.39-6.50) \\
P=0.005\end{array}$ & $\begin{array}{l}1.96(0.96-4.03) \\
P=0.07\end{array}$ & $\begin{array}{l}1.90(0.96-3.77) \\
P=0.07\end{array}$ & 1.00 & $\begin{array}{l}1.92(1.01-3.66) \\
P=0.05\end{array}$ & $\begin{array}{l}2.63(1.39-5.00) \\
P=0.003\end{array}$ & $\begin{array}{l}3.04(1.67-5.51) \\
P<0.001\end{array}$ \\
\hline $\begin{array}{l}\text { Model } 2 \\
(\mathrm{HR}, 95 \% \mathrm{Cl})\end{array}$ & $\begin{array}{l}3.68(1.68-8.05) \\
P=0.001\end{array}$ & $\begin{array}{l}2.11(1.02-4.34) \\
P=0.04\end{array}$ & $\begin{array}{l}2.07(1.04-4.11) \\
P=0.04\end{array}$ & 1.00 & $\begin{array}{l}1.69(0.89-3.24) \\
P=0.11\end{array}$ & $\begin{array}{l}2.30(1.20-4.39) \\
P=0.01\end{array}$ & $\begin{array}{l}2.50(1.37-4.57) \\
P=0.003\end{array}$ \\
\hline $\begin{array}{l}\text { Born } \geq 1940^{\&} \\
\text { cohort }\end{array}$ & 1107 & 2151 & 2180 & 1889 & 1780 & 1043 & 1416 \\
\hline No. of deaths & $2(0.002)$ & $12(0.006)$ & $8(0.004)$ & $11(0.006)$ & $12(0.007)$ & $9(0.009)$ & $4(0.003)$ \\
\hline $\begin{array}{l}\text { Model } 1 \\
(\mathrm{HR}, 95 \% \mathrm{Cl})\end{array}$ & $\begin{array}{l}0.33(0.07-1.50) \\
P=0.15\end{array}$ & $\begin{array}{l}0.97(0.43-2.21) \\
P=0.95\end{array}$ & $\begin{array}{l}0.65(0.26-1.63) \\
P=0.36\end{array}$ & 1.00 & $\begin{array}{l}1.17(0.52-2.65) \\
P=0.71\end{array}$ & $\begin{array}{l}1.49(0.62-3.59) \\
P=0.38\end{array}$ & $\begin{array}{l}0.48(0.15-1.51) \\
P=0.21\end{array}$ \\
\hline $\begin{array}{l}\text { Model } 2 \\
(\mathrm{HR}, 95 \% \mathrm{Cl})\end{array}$ & $\begin{array}{l}0.37(0.08-1.69) \\
P=0.20\end{array}$ & $\begin{array}{l}1.14(0.50-2.60) \\
P=0.76\end{array}$ & $\begin{array}{l}0.70(0.28-1.76) \\
P=0.45\end{array}$ & 1.00 & $\begin{array}{l}1.14(0.50-2.61) \\
P=0.75\end{array}$ & $\begin{array}{l}1.35(0.56-3.30) \\
P=0.51\end{array}$ & $\begin{array}{l}0.42(0.13-1.34) \\
P=0.14\end{array}$ \\
\hline
\end{tabular}

${ }_{\$}$ Postmenopausal women born before 1940 were analysed; \&Postmenopausal women born in 1940 or later were analysed; model 1: a crude hazard ratio model without adjustments; model 2: a multivariate adjusted model including age, diabetes, hypertension, dyslipidaemia, smoking, alcohol drinking, physical activity, body mass index, self-rated health, education, job, family income, number of children and oral contraceptive pill use 
Table 3 Association between fatal stroke occurrence and age at menopause in the GBCS

\begin{tabular}{|c|c|c|c|c|c|}
\hline & \multicolumn{5}{|l|}{ Age at menopause (years) } \\
\hline & $<43$ & $43-47$ & $48-50$ & $51-52$ & $\geq 53$ \\
\hline Total cohort & 940 & 2805 & 6600 & 2928 & 3231 \\
\hline No. of deaths & $26(0.028)$ & $42(0.015)$ & $88(0.013)$ & $31(0.010)$ & $35(0.010)$ \\
\hline $\begin{array}{l}\text { Model } 1 \\
\text { (HR, 95\% Cl) }\end{array}$ & $2.58(1.53-4.35), P<0.001$ & $1.40(0.88-2.23), P=0.16$ & $1.25(0.83-1.88), P=0.29$ & 1.00 & $0.98(0.61-1.59), P=0.94$ \\
\hline $\begin{array}{l}\text { Model } 2 \\
(\mathrm{HR}, 95 \% \mathrm{Cl})\end{array}$ & $1.64(0.97-2.78), P=0.06$ & $1.09(0.69-1.74), P=0.71$ & $1.10(0.73-1.65), P=0.66$ & 1.00 & $0.99(0.61-1.61), P=0.96$ \\
\hline Born $<1940^{\$}$ cohort & 413 & 981 & 1996 & 752 & 796 \\
\hline No. of deaths & $22(0.053)$ & $36(0.037)$ & $62(0.031)$ & $18(0.024)$ & $26(0.033)$ \\
\hline $\begin{array}{l}\text { Model } 1 \\
(\mathrm{HR}, 95 \% \mathrm{Cl})\end{array}$ & $2.30(1.23-4.28), P=0.009$ & $1.52(0.86-2.67), P=0.15$ & $1.29(0.77-2.18), P=0.34$ & 1.00 & $1.33(0.73-2.42), P=0.35$ \\
\hline $\begin{array}{l}\text { Model } 2 \\
(\mathrm{HR}, 95 \% \mathrm{Cl})\end{array}$ & $1.97(1.05-3.69), P=0.03$ & $1.43(0.81-2.52), P=0.22$ & $1.25(0.74-2.11), P=0.41$ & 1.00 & $1.35(0.74-2.47), P=0.33$ \\
\hline Born $\geq 1940^{\&}$ cohort & 527 & 1824 & 4604 & 2176 & 2435 \\
\hline No. of deaths & $4(0.008)$ & $6(0.003)$ & $26(0.006)$ & $13(0.006)$ & $9(0.004)$ \\
\hline $\begin{array}{l}\text { Model } 1 \\
(\mathrm{HR}, 95 \% \mathrm{Cl})\end{array}$ & $1.24(0.41-3.81), P=0.71$ & $0.55(0.21-1.46), P=0.23$ & $0.94(0.48-1.83), P=0.86$ & 1.00 & $0.59(0.25-1.38), P=0.22$ \\
\hline $\begin{array}{l}\text { Model } 2 \\
(\mathrm{HR}, 95 \% \mathrm{Cl})\end{array}$ & $1.00(0.32-3.08), P=0.99$ & $0.52(0.20-1.37), P=0.19$ & $0.92(0.47-1.79), P=0.80$ & 1.00 & $0.54(0.23-1.27), P=0.16$ \\
\hline
\end{tabular}

$\$$ Postmenopausal women born before 1940 were analysed; \&Postmenopausal women born in 1940 or later were analysed; model 1: a crude hazard ratio model without adjustments; model 2: a multivariate adjusted model including age, diabetes, hypertension, dyslipidaemia, smoking, alcohol drinking, physical activity, body mass index, self-rated health, education, job, family income, number of children and oral contraceptive pill use

$(\mathrm{aHR}=1.97,95 \%$ CI 1.05-3.69). However, there were no significant associations between fatal stroke and menopause in those born in 1940 or later. These associations were still observed in a sensitivity analysis after excluding uterus removal, ovaries, breast masses (benign or malignant) or hormone replacement therapy (Additional file 1: Table 2).

\section{Reproductive years in relation to fatal stroke occurrence}

Table 4 shows reproductive years in relation to fatal stroke occurrence. Compared with those with a number of reproductive years from 32 to 34, those with a number of reproductive years $\leq 28$ had an increased risk of fatal stroke $(\mathrm{aHR}=1.91,95 \% \mathrm{CI} 1.28-2.86)$ in the whole cohort, and similar associations were found for fatal

Table 4 Association between fatal stroke occurrence and reproductive years in the GBCS

\begin{tabular}{|c|c|c|c|c|c|}
\hline & \multicolumn{5}{|c|}{ Duration of reproductive years } \\
\hline & $\leq \mathbf{2 8}$ & $29-31$ & $32-34$ & $35-37$ & $\geq 38$ \\
\hline Total cohort & 1511 & 2193 & 4025 & 5114 & 3661 \\
\hline No. of deaths & $49(0.032)$ & $32(0.015)$ & $49(0.012)$ & $58(0.011)$ & $36(0.010)$ \\
\hline Model $1(\mathrm{HR}, 95 \% \mathrm{Cl})$ & $2.69(1.81-4.00), P<0.001$ & $1.18(0.76-1.85), P=0.46$ & 1.00 & $0.90(0.61-1.33), P=0.60$ & $0.81(0.52-1.24), P=0.33$ \\
\hline Model 2 (HR, 95\% Cl) & $1.91(1.28-2.86), P=0.001$ & $0.97(0.62-1.52), P=0.90$ & 1.00 & $1.09(0.74-1.61), P=0.65$ & $1.11(0.72-1.72), P=0.64$ \\
\hline Born $<1940^{\$}$ cohort & 713 & 878 & 1283 & 1293 & 771 \\
\hline No. of deaths & $41(0.058)$ & $29(0.033)$ & $38(0.030)$ & $33(0.026)$ & $23(0.030)$ \\
\hline Model 1 (HR, 95\% Cl) & $2.03(1.30-3.15), P=0.002$ & $1.13(0.70-1.83), P=0.62$ & 1.00 & $0.86(0.54-1.36), P=0.51$ & $1.00(0.60-1.68), P=0.99$ \\
\hline Model 2 (HR, 95\% Cl) & $1.79(1.15-2.80), P=0.01$ & $1.05(0.65-1.71), P=0.83$ & 1.00 & $0.89(0.56-1.42), P=0.62$ & $1.14(0.67-1.93), P=0.62$ \\
\hline Born $\geq 1940^{\&}$ cohort & 798 & 1315 & 2742 & 3821 & 2890 \\
\hline No. of deaths & $8(0.010)$ & $3(0.002)$ & $11(0.004)$ & $25(0.006)$ & $13(0.004)$ \\
\hline Model 1 (HR, 95\% Cl) & $2.51(1.01-6.25), P=0.047$ & $0.56(0.16-2.01), P=0.37$ & 1.00 & $1.50(0.73-3.07), P=0.27$ & $1.10(0.50-2.47), P=0.81$ \\
\hline Model 2 (HR, 95\% Cl) & $2.11(0.84-5.27), P=0.11$ & $0.52(0.14-1.86), P=0.31$ & 1.00 & $1.63(0.79-3.36), P=0.19$ & $1.13(0.51-2.55), P=0.76$ \\
\hline
\end{tabular}


stroke $(\mathrm{aHR}=1.79,95 \%$ CI $1.15-2.80)$ in the cohort of postmenopausal women born before 1940. Moreover, no reproductive years in relation to fatal stroke were observed in the cohort born in 1940 or later. Such associations were still observed in a sensitivity analysis after exclusion of those who had removal of the uterus, ovaries, or breast masses (benign or malignant) or received hormone replacement therapy (Additional file 1: Table 3).

\section{Discussion}

In this study, we found that younger and older menarche, early menopause and fewer reproductive years were related to an increased risk of fatal stroke in Chinese postmenopausal women. The association was independent of age, diabetes, hypertension, dyslipidaemia, smoking, alcohol consumption, physical activity, body mass index, self-rated health, education, job, family income, number of children and oral contraceptive pill use.

Previous studies are inconsistent in terms of the association between age at menarche and stroke [8-12, 16$19,24,25]$. In a previous cohort study of 37,965 Japanese postmenopausal women, age $\geq 17$ years at menarche was associated with a increased risk of mortality from stroke compared with age at menarche $\leq 13$ years [19], and a cohort study of 66,104 Korean women showed that women with age at menarche $\geq 17$ years had higher risks for total stroke and thrombotic stroke compared with age at menarch of 13-14 years [25]. Our findings were similar in that late menarche was associated with an increased risk of fatal stroke occurrence. A U-shaped relationship between both early and late menarche and the increased risk of stroke incidence was observed in 1.2 million British women aged 50 to 64 years without prior heart disease, stroke, or cancer. This finding is the same as ours, wherein fatal stroke occurrence occurred in older women born before 1940 but not born after the 1960s in China [14]. However, our results were not conclusive due to very small number of events, and large prospective studies are needed to replicate our findings.

It remains unclear why menarche is related to stroke events. We observed that menarche in relation to fatal stroke occurrence was independent of removal of the uterus, ovaries, or breast masses (benign or malignant) or use of hormone replacement therapy, and.the associations remained after further analysis of never smoking and additional adjustments for childhood passive smoking exposure, which suggests that these associations may be influenced by other risk factors. As in a previous study addressing early menarche in relation to metabolic syndrome and its components [31, 35], our results were independent of BMI, hypertension, diabetes, and other lifestyle and cardiovascular risk factors. Moreover, other unmeasured factors, including lower birth weight, higher body weight and weight gain in infancy and childhood, may be related to age at menarche and increase the risk of early menarche [36]. Additionally, in utero exposure and active physical activity during pregnancy [37] may be related to a modest delay in age at menarche among offspring. Anorexia, malnutrition and premenarchal intense exercise training are related to delayed menarche $[38,39]$. Thus, a U-shaped association here may be due to unmeasured but unrelated genetic factors [40].

There is an inconsistent association between menopause and stroke $[10-13,15,19-23,26]$. Women aged 80 years or older, but not those aged $<80$ years, who were $<40$ years old at menopause had a 2.29 times higher stroke mortality risk than those aged $45-49$ years at menopause [13]. Here, a lower age at menopause ( $<43$ years) was associated with higher fatal stroke occurrence in older generations born before 1940 but not in those born in 1940 or later. However, other reports show inconsistent findings [19-21, 23].

Early menopause in relation to the risk of fatal stroke occurrence is due mainly to changes in endogenous steroid hormones, especially oestradiol, after menopause [41, 42]. Oestradiol should be a protective factor in stroke, although hormone replacement therapy does not play a beneficiary role $[43,44]$. In our study, the proportion of induced menopause is $8.6 \%$, and a similar association released regardless of whether a series of factors or adjusted for lifestyle and cardiovascular risk factors were excluded. For aught we know, the effect of early menopause on fatal stroke may due to other risk factors.

The reproductive years constitute the interval between menarche and menopause. Most studies have reported that a low number of reproductive years is related to an increased fatal stroke or stroke incidence [10, 12, 25-27], though there are contradictory reports $[8,19]$. Here, fewer reproductive years ( $\leq 28$ years) was associated with an increased fatal stroke occurrence, which is consistent with a Korean cohort study addressing an increased risk for developing stroke and thrombotic stroke [25] and a case-control study on nonembolic ischaemic stroke risk [12]. Similar associations for fatal stroke were reported only by three teams: one in China and two in the United States [10, 26, 27]. An inconsistent relationship between reproductive years and fatal stroke occurrence was observed in China and Japan $[8,19]$.

In this study, 1940 was chose as a cut-point and two birth cohorts were added (the cohort born $\geq 1940$, the cohort born $<1940$ ) for further analysis (Additional file 1: Table 4). The reasons are that age at menarche among Chinese women droped with years, besides an anomalous increase during the 1958-61 national famine, and the menarche ended among most women born before 1940 [14]. Corresponding results showed that the 
cohort born $<1940$ had more fatal stroke occurrence than the cohort born $\geq 1940$ (Additional file 1: Table 4). This revealed that the younger cohort was not old enough to develop stroke events, although a limitation of low statistical power was released.

In our study, a median follow-up of 12.0 years makes this a large, prospective design for a study of the general population in South China, and individuals completed a physical examination and questionnaire involving a total of 800 questions. Thus, the acquired information allows for systemic adjustments for additional potential confounding factors. However, there are limitations in this study. First, we obtained only the death information via record linkage with the GZCDC. The results of our study with death as the only outcome are obviously weakened because of the lack of analysis of other clinical outcomes of stroke events. Second, among a series of potential confounders, there may be some inaccuracies in the risk factors, such as self-reported age at menarche and menopause, from the multi-year recall [45-47]. Third, the subjects could not represent Chinese individuals due to the limitations involving the general population in South China in this study. Finally, the small number of deaths limited the strength of this study to address fatal stroke, especially in a younger cohort.

\section{Conclusion}

Age at menarche, age at menopause and number of reproductive years were related to the risk of fatal stroke occurrence. The burden of stroke may be increased in certain populations, and such women should be given more attention during the decade after menopause.

\section{Abbreviations}

HR: Hazard ratio; Cl: Confidence interval; GBCS: Guangzhou Biobank Cohort Study; GZCDC: Guangzhou Centers for Disease Control and Prevention; ICD: International Classification of Diseases; IVT: Intravenous thrombolysis; IPAQ: International Physical Activity Questionnaire; OC: Oral contraceptive.

\section{Supplementary Information}

The online version contains supplementary material available at https://doi. org/10.1186/s12905-021-01579-9.

Additional file 1. Table 1. Association between fatal stroke occurrence and age at menarche after a series of exclusions in the GBCS\$: Postmenopausal women born before 1940 were analyzed; model 1: a crude hazard ratio model without adjustments; model 2: a multivariate adjust model including age, diabetes, hypertension, dyslipidemia, smoking, alcohol drinking, physical activity, body mass index, self-rated health, education, job, family income, number of children and oral contraceptive pill use. Table 2. Association between fatal stroke occurrence and age at menopause after a series of exclusions in the GBCS. \$: Postmenopausal women born before 1940 were analyzed; model 1: a crude hazard ratio model without adjustments; model 2: a multivariate adjust model including age, diabetes, hypertension, dyslipidemia, smoking, alcohol drinking, physical activity, body mass index, self-rated health, education, job, family income, number of children and oral contraceptive pill use. Table 3. Association between stroke mortality and duration of reproductive years after a series of exclusions in the GBCS. \$: Postmenopausal women born before 1940 were analyzed; model 1: a crude hazard ratio model without adjustments; model 2: a multivariate adjust model including age, diabetes, hypertension, dyslipidemia, smoking, alcohol drinking, physical activity, body mass index, self-rated health, education, job, family income, number of children and oral contraceptive pill use. Table 4. Baseline characteristics of two birth cohorts in the GBCS. Hypertension: systolic blood pressure, $\geq 140 \mathrm{mmHg}$, diastolic blood pressure, $\leq 90 \mathrm{mmHg}$, medication or diagnosed; diabetes: fasting blood glucose $\geq 7$ or medication or diagnosis; dyslipidaemia: total cholesterol $\geq 5.2 \mathrm{mmol} / \mathrm{L}$, triglyceride $\geq 1.7 \mathrm{mmol} / \mathrm{L}$, low density lipoprotein $\geq 3.4 \mathrm{mmol} / \mathrm{L}$, high density lipoprotein < $1.0 \mathrm{mmol} / \mathrm{L}$, medication or diagnosis; BMl: body mass index. SD: standard deviation. Table 5. Baseline characteristics of two types of samples in the GBCS. Hypertension: systolic blood pressure, $\geq 140 \mathrm{mmHg}$, diastolic blood pressure, $\leq 90 \mathrm{mmHg}$, medication or diagnosed; diabetes: fasting blood glucose $\geq 7$ or medication or diagnosis; dyslipidaemia: total cholesterol $\geq 5.2 \mathrm{mmol} / \mathrm{L}$, triglyceride $\geq 1.7 \mathrm{mmol} / \mathrm{L}$, low density lipoprotein $\geq 3.4 \mathrm{mmol} / \mathrm{L}$, high density lipoprotein $<1.0 \mathrm{mmol} / \mathrm{L}$, medication or diagnosis; BMI: body mass index. SD: standard deviation. Q25: the 25th quartile; Q75: the 75th quartile.

\section{Acknowledgements}

The Guangzhou Biobank Cohort Study investigators included Guangzhou Twelfth People's Hospital: Weisen Zhang, Min Cao, Tong Zhu, Bin Liu, and Caoqiang Jiang (Co-PI); The University of Hong Kong: C.M. Schooling, S.M. McGhee, G.M. Leung, R. Fielding, and Taihing Lam (Co-PI); The University of Birmingham: P. Adab, G. Neil Thomas, and Karkeung Cheng (Co-PI).

\section{Authors' contributions}

FZ contributed to the study design. ZBH and ZXL contributed to data collection and analysis. ZXL wrote, and FZ revised the manuscript. All authors read and approved the final manuscript.

\section{Funding}

This work was supported by the Guangzhou Science and Technology Bureau, Guangzhou, China (201704030132, 202102080467) and Guangdong Provincial Medical Science Research Foundation, Guangdong, China (A2021124).

\section{Availability of data and materials}

Data used in this analysis are available from the corresponding author on reasonable request.

\section{Declarations}

\section{Ethics approval and consent to participate}

Our study was approved by the Guangzhou Medical Ethics Committee of the Chinese Medical Association, and all participants provided written informed consent before participation in the GBCS. All methods in this study were performed in accordance with the Declaration of Helsinki.

\section{Consent for publication}

Not applicable.

\section{Competing interests}

The authors declare that they have no competing interests.

\section{Author details}

${ }^{1}$ Department of Internal Medicine and Central Laboratory, Guangzhou Twelfth People's Hospital, No. 1 Tianqiang St., Huangpu Rd., Guangzhou 510620, China. ${ }^{2}$ Department of Internal Medicine, Sanya Central Hospital, No. 1154 Jiefang Rd., Sanya 572019, China.

Received: 30 July 2021 Accepted: 21 December 2021

Published online: 28 December 2021 


\section{References}

1. Group GBDNDC. Global, regional, and national burden of neurological disorders during 1990-2015: a systematic analysis for the Global Burden of Disease Study 2015. Lancet Neurol. 2017;16(11):877-97.

2. Zhou M, Wang H, Zhu J, Chen W, Wang L, Liu S, Li Y, Wang L, Liu Y, Yin P, et al. Cause-specific mortality for 240 causes in China during 1990-2013: a systematic subnational analysis for the Global Burden of Disease Study 2013. Lancet. 2016;387(10015):251-72

3. McCullough LD, Mirza MA, Xu Y, Bentivegna K, Steffens EB, Ritzel R, Liu F. Stroke sensitivity in the aged: sex chromosome complement vs. gonadal hormones. Aging. 2016;8(7):1432-41.

4. Leening MJ, Ferket BS, Steyerberg EW, Kavousi M, Deckers JW, Nieboer D, Heeringa J, Portegies ML, Hofman A, Ikram MA, et al. Sex differences in lifetime risk and first manifestation of cardiovascular disease: prospective population based cohort study. BMJ. 2014;349:95992.

5. Wieberdink RG, Ikram MA, Hofman A, Koudstaal PJ, Breteler MM. Trends in stroke incidence rates and stroke risk factors in Rotterdam, the Netherlands from 1990 to 2008. Eur J Epidemiol. 2012;27(4):287-95.

6. Spaander FH, Zinkstok SM, Baharoglu IM, Gensicke H, Polymeris A, Traenka C, Hametner C, Ringleb P, Curtze S, Martinez-Majander N, et al. Sex differences and functional outcome after intravenous thrombolysis. Stroke. 2017:48(3):699-703.

7. Soriano-Reixach MM, Vivanco-Hidalgo RM, Ois A, Rodriguez-Campello A, Roquer J. Interaction of sex and diabetes on outcome after ischemic stroke. Front Neurol. 2018;9:250.

8. Wu X, Cai H, Kallianpur A, Gao YT, Yang G, Chow WH, Li HL, Zheng W, Shu $X O$. Age at menarche and natural menopause and number of reproductive years in association with mortality: results from a median follow-up of 11.2 years among 31,955 naturally menopausal Chinese women. PLoS ONE. 2014;9(8):e103673

9. Jacobsen BK, Heuch I, Kvale G. Age at natural menopause and stroke mortality: cohort study with 3561 stroke deaths during 37-year follow-up. Stroke. 2004:35(7):1548-51.

10. Ley SH, Li Y, Tobias DK, Manson JE, Rosner B, Hu FB, Rexrode KM. Duration of reproductive life span, age at menarche, and age at menopause are associated with risk of cardiovascular disease in women. J Am Heart Assoc. 2017. https://doi.org/10.1161/JAHA.117.006713.

11. Murakami K, Metoki H, Satoh M, Asayama K, Hosaka M, Matsuda A, Inoue R, Tsubota-Utsugi M, Murakami T, Nomura K, et al. Menstrual factors and stroke incidence in japanese postmenopausal women: the Ohasama Study. Neuroepidemiology. 2016;47(2):109-16.

12. Alonso de Lecinana M, Egido JA, Fernandez C, Martinez-Vila E, Santos S, Morales A, Martinez E, Pareja A, Alvarez-Sabin J, Casado I, et al. Risk of ischemic stroke and lifetime estrogen exposure. Neurology. 2007;68(1):33-8.

13. Hong JS, Yi SW, Kang HC, Jee SH, Kang HG, Bayasgalan G, Ohrr H. Age at menopause and cause-specific mortality in South Korean women: Kangwha Cohort Study. Maturitas. 2007;56(4):411-9.

14. Yang L, Li L, Millwood IY, Peters SAE, Chen Y, Guo Y, Bian Z, Chen X, Chen L, Feng $S$, et al. Age at menarche and risk of major cardiovascular diseases: evidence of birth cohort effects from a prospective study of 300,000 Chinese women. Int J Cardiol. 2017;227:497-502.

15. Liberale L, Montecucco F, Bonaventura A, Casetta I, Seraceni S, Trentini A, Padroni M, Dallegri F, Fainardi E, Carbone F. Monocyte count at onset predicts poststroke outcomes during a 90-day follow-up. Eur J Clin Investig. 2017:47(10):702-10

16. Charalampopoulos D, McLoughlin A, Elks CE, Ong KK. Age at menarche and risks of all-cause and cardiovascular death: a systematic review and meta-analysis. Am J Epidemiol. 2014;180(1):29-40.

17. Gallagher LG, Davis LB, Ray RM, Psaty BM, Gao DL, Checkoway H, Thomas DB. Reproductive history and mortality from cardiovascular disease among women textile workers in Shanghai, China. Int J Epidemiol. 2011;40(6):1510-8.

18. Mueller NT, Odegaard AO, Gross MD, Koh WP, Yuan JM, Pereira MA Age at menarche and cardiovascular disease mortality in Singaporean Chinese women: the Singapore Chinese Health Study. Ann Epidemiol. 2012;22(10):717-22

19. Cui R, Iso H, Toyoshima H, Date C, Yamamoto A, Kikuchi S, Kondo T, Watanabe Y, Koizumi A, Inaba Y, et al. Relationships of age at menarche and menopause, and reproductive year with mortality from cardiovascula disease in Japanese postmenopausal women: the JACC study. J Epidemiol. 2006;16(5):177-84.

20. Mondul AM, Rodriguez C, Jacobs EJ, Calle EE. Age at natural menopause and cause-specific mortality. Am J Epidemiol. 2005;162(11):1089-97.

21. Jacobsen BK, Oda K, Knutsen SF, Fraser GE. Age at menarche, total mortality and mortality from ischaemic heart disease and stroke: the Adventist Health Study, 1976-88. Int J Epidemiol. 2009:38(1):245-52.

22. Hu FB, Grodstein F, Hennekens CH, Colditz GA, Johnson M, Manson JE, Rosner B, Stampfer MJ. Age at natural menopause and risk of cardiovascular disease. Arch Intern Med. 1999;159(10):1061-6.

23. de Kleijn MJ, van der Schouw YT, Verbeek AL, Peeters PH, Banga JD, van der Graaf Y. Endogenous estrogen exposure and cardiovascular mortality risk in postmenopausal women. Am J Epidemiol. 2002;155(4):339-45.

24. Canoy D, Beral V, Balkwill A, Wright FL, Kroll ME, Reeves GK, Green J, Cairns BJ. Million Women Study C: age at menarche and risks of coronary heart and other vascular diseases in a large UK cohort. Circulation. 2015;131(3):237-44

25. Jung KJ, Kim MR, Yun YD, Kim HC, Jee SH. Duration of ovarian hormone exposure and atherosclerotic cardiovascular disease in Korean women: the Korean Heart Study. Menopause. 2016:23(1):60-6.

26. Yang L, Lin L, Kartsonaki C, Guo Y, Chen Y, Bian Z, Xie K, Jin D, Li L, Lv J, et al. Menopause characteristics, total reproductive years, and risk of cardiovascular disease among Chinese women. Circ Cardiovasc Qual Outcomes. 2017. https://doi.org/10.1161/CIRCOUTCOMES.117.004235.

27. Mansoor H, Elgendy IY, Segal R, Hartzema A. Duration of reproductive years and the risk of cardiovascular and cerebrovascular events in older women: insights from the National Health and Nutrition Examination Survey. J Womens Health. 2017;26(10):1047-52.

28. Lewington S, Li L, Murugasen S, Hong LS, Yang L, Guo Y, Bian Z, Collins R, Chen J, He H, et al. Temporal trends of main reproductive characteristics in ten urban and rural regions of China: the China Kadoorie biobank study of 300000 women. Int J Epidemiol. 2014;43(4):1252-62.

29. Jiang C, Thomas GN, Lam TH, Schooling CM, Zhang W, Lao X, Adab P, Liu B, Leung GM, Cheng KK. Cohort profile: the Guangzhou Biobank Cohort Study, a Guangzhou-Hong Kong-Birmingham collaboration. Int J Epidemiol. 2006;35(4):844-52.

30. Deng HB, Macfarlane DJ, Thomas GN, Lao XQ, Jiang CQ, Cheng KK, Lam TH. Reliability and validity of the IPAQ-Chinese: the Guangzhou Biobank Cohort study. Med Sci Sports Exerc. 2008;40(2):303-7.

31. Heys M, Schooling CM, Jiang C, Cowling BJ, Lao X, Zhang W, Cheng KK, Adab P, Thomas GN, Lam TH, et al. Age of menarche and the metabolic syndrome in China. Epidemiology. 2007;18(6):740-6.

32. Yang $S$, Jin Y, He Y, Jiang C, Cheng KK, Zhang W, Lam TH. Childhood passive smoking exposure and age at menarche in Chinese women who had never smoked: the Guangzhou Biobank Cohort Study. PLoS ONE. 2015;10(7):e0130429.

33. Ertunc D, Tok EC, Aytan H, Gozukara YM. Passive smoking is associated with lower age at menopause. Climacteric. 2015;18(1):47-52.

34. Hou L, Han W, Jiang J, Liu B, Wu Y, Zou X, Xue F, Chen Y, Zhang B, Pang $H$, et al. Passive smoking and stroke in men and women: a national population-based case-control study in China. Sci Rep. 2017:7:45542.

35. Chang CJ, Lai MM, Lin CC, Liu CS, Li TC, Li Cl, Lin WY. Age at menarche and its association with the metabolic syndrome in Taiwan. Obes Res Clin Pract. 2016;10(Suppl 1):S26-34.

36. Juul F, Chang VW, Brar P, Parekh N. Birth weight, early life weight gain and age at menarche: a systematic review of longitudinal studies. Obes Rev. 2017;18(11):1272-88

37. Colbert LH, Graubard BI, Michels KB, Willett WC, Forman MR. Physical activity during pregnancy and age at menarche of the daughter. Cancer Epidemiol Biomarkers Prev. 2008;17(10):2656-62.

38. Rees M. Menarche when and why? Lancet. 1993;342(8884):1375-6.

39. Rosetta L. Female reproductive dysfunction and intense physical training. Oxf Rev Reprod Biol. 1993;15:113-41.

40. He C, Kraft P, Chasman DI, Buring JE, Chen C, Hankinson SE, Pare G, Chanock S, Ridker PM, Hunter DJ. A large-scale candidate gene association study of age at menarche and age at natural menopause. Hum Genet. 2010;128(5):515-27

41. Cai J, Li J, Chen S, Meng J, Ren R, Li M. Early post-haemorrhagic stroke testosterone and oestradiol levels and long-term risk of death. Brain Inj. 2017;31(3):401-5 
42. Guo JM, Shu H, Wang L, Xu JJ, Niu XC, Zhang L. SIRT1-dependent AMPK pathway in the protection of estrogen against ischemic brain injury. CNS Neurosci Ther. 2017;23(4):360-9.

43. Brass LM. Hormone replacement therapy and stroke: clinical trials review. Stroke. 2004;35(11 Suppl 1):2644-7.

44. Bath PM, Gray LJ. Association between hormone replacement therapy and subsequent stroke: a meta-analysis. BMJ. 2005;330(7487):342.

45. Must A, Phillips SM, Naumova EN, Blum M, Harris S, Dawson-Hughes B, Rand WM. Recall of early menstrual history and menarcheal body size: after 30 years, how well do women remember? Am J Epidemiol. 2002;155(7):672-9.

46. Lundblad MW, Jacobsen BK. The reproducibility of self-reported age at menarche: The Tromso Study. BMC Womens Health. 2017;17(1):62.

47. Colditz GA, Stampfer MJ, Willett WC, Stason WB, Rosner B, Hennekens $\mathrm{CH}$, Speizer FE. Reproducibility and validity of self-reported menopausal status in a prospective cohort study. Am J Epidemiol. 1987;126(2):319-25.

\section{Publisher's Note}

Springer Nature remains neutral with regard to jurisdictional claims in published maps and institutional affiliations.

- fast, convenient online submission

- thorough peer review by experienced researchers in your field

- rapid publication on acceptance

- support for research data, including large and complex data types

- gold Open Access which fosters wider collaboration and increased citations

- maximum visibility for your research: over $100 \mathrm{M}$ website views per year

At BMC, research is always in progress.

Learn more biomedcentral.com/submissions 